\title{
OS EFEITOS DAS BARREIRAS TARIFÁRIAS SOBRE AS EXPORTAÇÕES BRASILEIRAS DE LATICÍNIOS ENTRE 2007 E 2016
}

\author{
The effects of trade barriers on Brazilian dairy exports between 2007 and 2016
}

\begin{abstract}
RESUMO
A exportação de produtos agroindustriais vem se tornando cada vez mais imperiosa para a economia brasileira e para o atendimento das demandas alimentares da população do mundo inteiro. No entanto, essas mercadorias estão sujeitas a pesadas barreiras comerciais unilaterais, servindo como exemplo o mercado mundial de laticínios. Em contrapartida, fóruns internacionais de comércio buscam incentivar acordos multilaterais entre os países em detrimento do protecionismo. No caso do Brasil, temos observado uma série de restrições ao comércio de lácteos que redundam em redução do volume total negociado. Diante desses fatores, este estudo buscou examinar o ambiente regulatório do comércio internacional de derivados do leite na tentativa de compreender a forma como os principais determinantes das exportações nacionais atuam sobre seus respectivos valores nominais. A partir da construção de modelos gravitacionais para dados em painel, os resultados encontrados não afastaram a hipótese de correlação negativa entre as variações do nível de proteção tarifária e o desempenho das exportações, sendo que outros preditores considerados, entre eles, a distância geográfica e a renda mundial se apresentaram igualmente significativos para a determinação das exportações de laticínios.
\end{abstract}

Thiago Fernandes Ladeira

Empresa de Pesquisa Agropecuária de Minas Gerais

fernandesladeira@hotmail.com

Leonardo Igor Araújo de Souza

Empresa de Pesquisa Agropecuária de Minas Gerais

leonardo.igoraraujo@gmail.com

Djalma Ferreira Pelegrini

Empresa de Pesquisa Agropecuária de Minas Gerais

djalma@epamig.br

Recebido em: 28/08/2019. Aprovado em: 14/08/2020.

Avaliado pelo sistema double blind review

Avaliador científico: Paulo Henrique Montagnana Vicente Leme

DOI: 10.48142/2238-68902019v21n1-3p131147

\begin{abstract}
The Brazilian agroindustrial exports have become increasingly imperative for the economy and to meet the food demands of the worldwide population. However, these commodities are subject to heavy unilateral trade barriers, serving as an example the world dairy market. In contrast, international trade forums seek to encourage multilateral agreements between countries at the expense of protectionism. In the case of Brazil, we have observed a series of restrictions on the dairy trade that result in a reduction in the total volume traded. Given these factors, this study sought to examine the regulatory environment of international trade in dairy products in an attempt to understand how the main determinants of national exports act on their respective nominal values. From the construction of gravitational models for panel data, the results found did not rule out the hypothesis of negative correlation between variations in the level of tariff protection and export performance, and other predictors considered, among them, geographical distance and world income were presented equally significant for the determination of dairy exports
\end{abstract}

Palavras-chave: Mercado Internacional. Agroindústria. Protecionismo.

Keywords: International Market. Agribusiness. Protectionism.

\section{INTRODUÇÃO}

A exploração da pecuária leiteira representa uma atividade produtiva de elevada importância econômica e cultural. Possivelmente, sua origem coincide com o início da própria civilização humana e da domesticação de animais, no limiar da chamada primeira revolução agrícola, aproximadamente há onze mil anos (CURRY, 2013).

Nos tempos atuais, a rica disponibilidade de produtos derivados do leite proporciona inúmeros benefícios para a saúde humana. Considerados alimentos de alta densidade de nutrientes e, ainda, importantes ingredientes complementares na culinária em geral (RENHE, 2008), fornecem até $14 \%$ das necessidades energéticas diárias de seis bilhões de pessoas, tendo, inclusive, o seu consumo duplicado nos países em desenvolvimento desde a década de 1960 (GEROSA; SKOET, 2013).

Deste ângulo, a relevância social da cadeia produtiva de lácteos assume um caráter incontestável se 
somarmos a todos estes aspectos a capacidade da atividade em manter o homem assentado no campo, auxiliando a estabilidade de fenômenos como o êxodo rural. Com isso, a expansão da sua produção, distribuição e comercialização, tanto doméstica quanto externa, dentro das técnicas e do manejo corretos, deve ser adequadamente incentivada.

Não obstante, o quadro observado especificamente no comércio internacional de laticínios passa ao largo do recomendado. Políticas de defesa dos preços internos e de exportação impostas através de taxas, subsídios, quotas e outros mecanismos, criam barreiras comerciais que extrapolam o usual e fazem do mercado internacional de laticínios um dos mais protegidos do mundo (SIQUEIRA; LINHARES; HOTT, 2011).

Além disso, as evidências disponíveis indicam uma queda na produção de leite experimentada por países e regiões com volume de produção relevante, entre eles Argentina, Austrália, Nova Zelândia e União Europeia (EU), cuja taxa de crescimento de apenas 0,5\% em 2017 contrasta com os 2,1\% da década imediatamente anterior, o que aliado à aquecida demanda chinesa por laticínios e às restrições de importação por parte da Rússia e do México pode implicar em volatilidade dos preços internacionais e um acirramento das condições de mercado nos próximos anos (OECD-FAO, 2018), agravando ainda mais o quadro de protecionismo comercial.

No caso brasileiro, dados do Ministério do Desenvolvimento, Indústria e Comércio (MDIC) para os anos de 2000 a 2017, mostram que a exportação de laticínios - considerados, grosso modo: leites concentrados, não concentrados, fermentados e acidificados, manteiga, queijos e soro de leite - apresentou valores reais de $\mathrm{R} \$$ 3.760 mil em 2000 e R\$ 102.550 mil em 2017, sendo que, com relação à concentração espacial da produção, vale destacar que das vinte e sete unidades da federação, apenas quatro, Minas Gerais, Paraná, Rio Grande do Sul e São Paulo, responderam por 93\% do volume comercializado. Contudo, mesmo tendo o valor real das exportações se multiplicado vinte e seis vezes, ainda persistem questões intrigantes como o fato de o país ser importador líquido de produtos como leite em pó e queijo.

Ademais, nas últimas quatro décadas, a produção brasileira de leite de vaca evoluiu de um patamar de 8.500 milhões de litros em 1975 para um valor estimado de 30.100 milhões em 2017 (IBGE, 2018), representando uma alta de $354 \%$; ao passo que, no mesmo período, a população do país partiu de um total de 107.200 mil habitantes para 207.800 mil, apontando elevação correspondente a 194\% (WORLD BANK, 2019).
De fato, considerando a perspectiva recente de estagnação da renda e do consumo de produtos derivados do leite (MILANEZ et al., 2018), caso mantidas taxas de crescimento da produção quase duas vezes superiores à variação populacional, o excedente potencialmente resultante precipitará a necessidade de acessar novas rotas de escoamento da produção, como alternativa de um enfrentamento contracíclico desta realidade.

Considerando tal estado de coisas, torna-se providencial debater e apresentar soluções para os desafios impostos à cadeia produtiva do leite e, neste contexto, o presente trabalho pretende oferecer como subsídio empírico o entendimento do ambiente regulatório internacional deste mercado na atualidade, bem como investigar possíveis determinantes das exportações brasileiras de laticínios e o modo como esses fatores se relacionam com o nível de exportações de lácteos.

Para tanto, serão levados em conta os valores nominais de exportação dos produtos classificados como derivados lácteos conforme a classificação internacional do Harmonized System (HS) para um painel de dados composto por uma amostra de 104 países - descritos em anexo - no período compreendido entre 2007 e 2016 . O fundamento para escolha específica do período relatado vem a ser a intenção de compreender o fenômeno estudado no contexto temporal pós-crise financeira de 2007.

A estratégia metodológica adotada envolveu a construção de modelos gravitacionais com parâmetros estimados pelo método de pseudo-máxima verossimilhança para distribuições de Poisson (PPML) e binomial negativa (NB), com a intenção de captar, por meio de magnitudes de elasticidades, um quadro de sensibilidade da variável dependente às variações quantitativas nas variáveis explanatórias.

Para buscar o intuito pretendido, o presente estudo conta com a seguinte estrutura: após esta breve introdução, o referencial teórico e a revisão bibliográfica envolvendo questões de políticas comerciais e do ambiente regulatório do comércio internacional de laticínios precedem a seção de metodologia e fonte dos dados. Na sequência, os resultados são apresentados junto com algumas discussões cabíveis. Como conclusão, as considerações finais trazem a síntese e os subsídios para políticas públicas.

\section{REFERENCIAL TEÓRICO}

Dado que o curso teórico e a prática do comércio internacional ocupam o escopo de uma ampla quantidade de trabalhos que já se encontram bem documentados tanto na literatura doméstica quanto na estrangeira - ver, 
entre outros, Helpman (1999) e Coutinho et al. (2005), procederemos a uma breve revisão bibliográfica de forma a cobrir tão somente os conceitos e conclusões gerais desse campo de pesquisa. Atenção maior será dispensada aos mecanismos e instrumentos de política comercial, por se tratar do aspecto mais importante para este ensaio.

Destarte, a teoria do comércio exterior e dos instrumentos de política comercial coincide com a fundação da própria Economia como disciplina autônoma. Ainda no século XVIII, pensadores clássicos defendiam um modelo de comércio internacional livre de intervenções e constrangimentos políticos em benefício da eficiência econômica e da maximização do bem estar coletivo; sendo esse o caso, por exemplo, do argumento das vantagens competitivas presente em Ricardo (1817:1982) e Smith (1776:1985).

Para além desses autores, Heckscher (1919:1991) e Ohlin (1933) propuseram um modelo de padrão de comércio exterior no qual a dotação de fatores de produção entre as nações definia o seu valor e, por extensão, seus custos relativos. Em consequência, dada a disponibilidade desses fatores, digamos trabalho e capital, cada país deveria se especializar na produção daqueles artigos cujo processo produtivo é intensivo no fator, relativamente, mais disponível. Com isso, o ótimo econômico ocorreria quando a produção internacional de manufaturas e commodities primárias estivesse bem dividida entre países ricos em capital e países abundantes em trabalho, respectivamente.

Contudo, nas últimas décadas, modelos teóricos baseados em regimes de concorrência monopolística, oligopólios e outras imperfeições de mercado têm sido desenvolvidos por autores como Krugman (1980). Por certo, houve um considerável ceticismo, no decorrer do tempo, sobre a capacidade das teorias de custos comparativos em conseguir explicar de forma abrangente os padrões de comércio internacional. $\mathrm{O}$ entendimento vigente é que seria difícil determinar uma teoria padrão que pudesse abarcar o extensivo comércio de países industriais e o comércio de trocas bidirecionais de produtos diferenciados. Diante disso, emergiu a necessidade de novas formas de se analisar o comércio entre as nações.

A noção de economias de escala na produção foi importante para ampliar a compreensão do comércio internacional na medida em que os agentes econômicos podem, por exemplo, diferenciar seus produtos sem qualquer custo: cada parte pode possuir um poder de monopólio, mas a abertura conduz os lucros monopolísticos a zero. A ideia subjacente sugere que quando duas economias imperfeitamente competitivas são levadas a negociar, retornos crescentes produzem ganhos de comércio, mesmo se as economias tiverem tecnologia e dotação de fatores idênticos. Por isso, Krugman (1980) sustentou que um cenário envolvendo economias de escala possui necessariamente aspectos mais dinâmicos que não poderiam ser tratados integralmente pelos antigos modelos de custos comparativos.

Assim como descrito, um aspecto fundamental dos referidos modelos de matizes liberais vem ser a noção de que a presença de obstáculos ao pleno desenvolvimento do comércio entre nações, digamos, barreiras tarifárias, assume um caráter teórica e politicamente injustificável, cabendo ao Estado o papel passivo de mero facilitador do trânsito de bens e serviços entre os países para que a inevitável trajetória das economias nacionais em direção à especialização produtiva possa ocorrer.

Novamente, as conclusões desta corrente de pensamento não tardaram a encontrar resistência, também, neste aspecto. Muito em função dos efeitos deletérios que a especialização internacional da produção vem provocando ao longo do tempo, autores como List (1841:1986) e Brocard (1929) - nos primórdios - até Hausmann e Hidalgo (2010), Hausmann, Hwang e Rodrik (2007), entre outros - mais recentemente - confrontaram os partidários do livre-cambismo e construíram argumentos favoráveis a práticas protecionistas com vistas à defesa da produção de setores sensíveis da economia doméstica, como parte de estratégias para superação do atraso econômico.

Neste ponto, o termo protecionismo pode ser definido como o conjunto de medidas que visam desencorajar as importações e estimular as exportações por meio da edição de leis e outros recursos normativos a fim de resguardar a produção doméstica da concorrência internacional, de acordo as demandas específicas de cada segmento.

Decerto, se no protecionismo direcionado ao setor industrial o que se pretende alcançar é o estímulo e a preservação das economias de escala, dos aumentos de produtividade e do progresso tecnológico típicos dessa atividade, na agricultura, os objetivos centrais são justificados pela instabilidade dos preços agrícolas, os riscos empresariais e ambientais, a segurança alimentar, a estabilidade social e o menor dinamismo e rentabilidade da produção (MORAES, 1996). Assim sendo, fica claro o quadro de motivações que faz a cadeia de laticínios suscetível a pesadas intervenções políticas, uma vez que nela estão presentes tanto tradicionais atividades primárias, quanto avançados processos produtivos das cadeias agroindustriais e alimentares.

Sobre estes pontos, podemos considerar que a viabilização de tais práticas protecionistas envolve a intervenção nos fluxos de comércio por meio da imposição 
de tarifas de importação, denominadas barreiras tarifárias (BT) - sendo, neste caso, o preço a variável de ajuste -, além das barreiras não tarifárias (BNT), no contexto das restrições referentes a volumes e quantidades.

Com respeito ao primeiro ponto, Habeler (1937) nos esclarece que barreiras tarifárias são aquelas em que o efeito líquido tende a deslocar volumes antes importados para os setores domésticos que produzam artigos idênticos ou substitutos próximos, sendo que, para esses setores, a demanda, consequentemente, se eleva. Por outro lado, tarifas aduaneiras simplesmente arrecadatórias ocorrem quando as mercadorias produzidas internamente estão sujeitas ao mesmo nível de taxação de seus similares importados, ou, ainda, se os bens estrangeiros sujeitos aos impostos de importação não são produzidos internamente nem existem substitutos cuja demanda seria deslocada por causa da tarifa.

Em contrapartida, Ederington e Ruta (2016) compreendem como barreiras não tarifárias todo ato que não represente tarifas de importação, porém tenha potencial para impactar o comércio. O conceito pode ser melhor compreendido se considerarmos que tais BNT's assumem, em suas formas típicas, restrições quantitativas e qualitativas sobre o volume ou o valor das importações, dentre as quais podemos citar as legislações fitossanitárias e as quotas de importação.

A relevância sistêmica de questões envolvendo obstruções ao comércio internacional pode ser confirmada diante dos esforços de liberalização comercial empreendidos ao longo da segunda metade do século passado. Após as experiências traumáticas legadas pela II Guerra Mundial, diversos grupos de países criaram redes de instituições que buscaram fomentar a internacionalização econômica e o comércio multilateral. $O$ resultado veio com a criação do Acordo Geral sobre Tarifas e Comércio (GATT), após os EUA convidarem os países aliados para a negociação de um acordo com a finalidade de redução recíproca das barreiras ao comércio mundial (MESQUITA, 2013).

Na prática, é possível afirmar que o GATT, cuja vigência se estendeu entre 1947 e 1994, apesar de ter defendido uma posição antiprotecionista, não chegava endossar o livrecambismo. Entretanto, a forte influência norte-americana e de outros países desenvolvidos nas decisões dos fóruns causou uma série de conflitos de interesses, principalmente com os países em desenvolvimento, que no geral defendiam pautas comerciais mais ligadas a áreas como têxteis e agricultura. Diante dessa assimetria de poder, o GATT, apesar de ter contribuído para a promoção do comércio multilateral e de acordos que reduziram tarifas alfandegárias, acabou substituído pela ideia de se estabelecer uma organização internacional que tratasse das questões relacionadas ao comércio internacional. Em outros termos: era preciso institucionalizar mecanismos capazes de exercer mais coerção sobre os países.

Sendo assim, a Organização Mundial do Comércio (OMC), ratificada em 1995, estabeleceu uma base jurídica própria e mais sólida no cenário internacional. A extinção de derrogações históricas (grandfather clause e waivers agrícolas), a obrigatoriedade de subscrição de todos os acordos por todos os membros, a instituição de um mecanismo compulsório de solução de controvérsias constituem um conjunto de mudanças de grande alcance que transformaram a face do sistema de comércio multilateral (MESQUITA, 2013).

Em particular para o mercado mundial de laticínios, conformou-se uma extensa pauta no âmbito dos fóruns internacionais. Como exemplo, em 1970, na Suíça, foi estabelecido na estrutura do GATT o "Arrangement Concerning Certain Dairy Products". A intenção desse acordo foi determinar um preço mínimo para o leite em pó desnatado com o objetivo de expandir o mercado do derivado lácteo para outros países. Em 1973, também na Suíça, foi acordado o "Protocol Relating to Milk Fat", que ampliou o controle de preços no setor de laticínios.

Contudo, o principal mecanismo de negociação elaborado especificamente para o mercado de lácteos foi dado por meio do "International Dairy Agreement" (IDA). Este acordo, estabelecido em 1980, teve a função de promover pautas que ampliassem a liberalização do comércio mundial de laticínios através da cooperação multilateral. Todavia, a aplicação prática dos acordos muitas vezes entrava em conflito com barreiras comerciais efetivamente aplicadas. Em seguida, o IDA foi incorporado à $\mathrm{OMC}$ no ano de 1995 tendo como membros Argentina, Bulgária, UE, Japão, Nova Zelândia, Romênia, Suíça e Uruguai. Por decisão do Conselho Internacional de Laticínios, o acordo foi, então, extinto no ano de 1998 em virtude de não dispor dos meios eficazes de punição para aqueles que o descumprissem. Além disso, os conflitos de interesse tornavam ainda mais difícil a viabilidade dos tratados. Destaca-se que, no setor de laticínios, as discordâncias entre os agentes nos fóruns internacionais geralmente envolviam o embate entre países de custos de produção estruturalmente baixos e aqueles de custos, relativamente, mais elevados, tais como os EUA e a UE.

Neste cenário, algumas investigações que examinam as repercussões econômicas das mais diversas práticas regulatórias e comerciais no alcance dos mercados agroindustriais internacionais auxiliam na compreensão 
do tema. A propósito, um estudo a respeito dos impactos da liberalização no comércio de laticínios sugere que os produtores de leite de baixo custo (e.g., MERCOSUL e Nova Zelândia) ganhariam ainda mais com uma completa liberalização do comércio (ZHU; COX; CHAVAS, 1999).

De forma convergente, as pesquisas de Alvim (2010), Griffith, Lattimore e Robertson (1993) e Siqueira, Linhares e Hott (2011), que abordam desde simulações de cenários de livre comércio multilateral frente à remoção de barreiras tarifárias até os efeitos de políticas domésticas no comércio internacional de derivados, concordam pela recomendação da redução dos custos do comércio de lácteos por intermédio do multilateralismo, em contraste com acordos regionais e bilaterais que protegem parceiros comerciais e reduzem os ganhos potenciais para a economia mundial.

Mais especificamente, Siqueira, Linhares e Hott (2011) nos mostram as políticas tarifárias para certa amostra de países. Após tabulação de dados do Market Access Map (Macmap) e do United Nations Commodity Trade Statistics Database (Comtrade), são apresentadas as tarifas aplicadas pelos principais parceiros dos maiores exportadores de soro de leite em 2010, a saber: Alemanha, EUA e Nova Zelândia. Seguindo a metodologia de Freitas e Costa (2005), foram calculadas estatísticas descritivas a fim de classificar os países em ordem decrescente de imposição tarifária. De acordo com as informações obtidas, a Alemanha - o principal exportador de soro de leite - tem os países da UE como seus maiores parceiros comerciais, devido à ausência de barreiras de comércio no bloco. Já os EUA e a Nova Zelândia, observa-se que são mais afetados pelas barreiras tarifárias, cobradas em grande medida pelos próprios países da UE, além do Japão e do Canadá.

Além disso, os países da UE, Japão, EUA, e Canadá, por exemplo, estão entre os que mais praticam políticas protecionistas. Já os EUA e a Nova Zelândia desfrutam de isenções tarifárias com os países nos quais possuem acordos regionais ou bilaterais, como o acordo EUA-México-Canadá $\left(\right.$ USMCA) ${ }^{1}$ e o acordo ANZCERTA (Austrália - Nova Zelândia). Dessa forma, apreendemos que a aplicação de barreiras tarifárias é ainda uma prática comum, apesar dos esforços de organismos multilaterais. No entanto, para os autores, devido às estimativas de ganho para a economia mundial de aproximadamente US\$ 175 bilhões, o comércio internacional estaria em melhor situação na ausência de barreiras comerciais (SIQUEIRA; LINHARES; HOTT, 2011).

${ }^{1}$ Em setembro de 2018, EUA, México e Canadá chegaram a um acordo para substituir o North American Free Trade Agreement (NAFTA) pelo United States-Mexico-Canada Agreement (USMCA). O NAFTA permanecerá em vigor, enquanto se aguarda a ratificação do USMCA.
Na pesquisa de Alvim (2010), o autor simula um cenário mundial de acordo multilateral de livre comércio utilizando técnicas de tabelamento dos resultados de variação na produção e no consumo. Os países utilizados na amostra foram Argentina, Brasil, Uruguai, Canadá, EUA, Austrália, Nova Zelândia, além de agregar a UE e o "resto do mundo" (RM) como regiões. Segundo o estudo, Canadá, EUA e UE são os maiores produtores de leite in natura e utilizam barreiras tarifárias e subsídios para manterem a posição privilegiada no mercado, sendo que os países do MERCOSUL (Argentina, Brasil, Uruguai) têm uma participação menor na produção e possuem tarifas mais baixas para compensar a perda de competitividade no setor. Por seus turnos, Austrália e Nova Zelândia figuram como os maiores exportadores líquidos, apesar de constituírem uma pequena parcela na produção e no consumo.

Para avaliar as variações (ganhos e perdas potenciais) em termos de produção, consumo e comércio, utilizou-se um modelo de equilíbrio parcial formulado como um Problema de Complementaridade Mista (MCP). Tal modelo considera multirregiões e multiprodutos, o que permitiu avaliar os efeitos de políticas de livre comércio para regiões e produtos distintos (ALVIM, 2010).

O objetivo foi avaliar os ganhos no mercado de laticínios em um contexto econômico multilateral, sem barreiras tarifárias e subsídios, em que os países atuam no comércio internacional de lácteos de acordo com suas potencialidades naturais e disposição em atender os consumidores. No cenário em que não há barreiras comerciais, o resultado mostra um aumento na produção de lácteos para os países do MERCOSUL e da Oceania, além de uma redução no consumo devido à internacionalização do comércio. Para Canadá, EUAe UE, houve diminuição na produção e aumento geral no consumo. Analisando as informações, este cenário multilateral promoveu ganhos para os países do MERCOSUL, da Oceania e para o "resto do mundo": o aumento na produção mundial proporcionou um mercado mais rentável e competitivo. Novamente, para Canadá, EUA e UE, com a eliminação das barreiras comerciais, a produção foi reduzida, apesar do aumento no consumo, fato que assinala maior poder aquisitivo nos mercados desses países.

Por fim, Griffith, Lattimore e Robertson (1993) apresentaram um modelo simplificado de comércio multilateral em equilíbrio parcial para produtos lácteos contendo cinco grandes regiões produtoras - Austrália, Comunidade Europeia (CE), Nova Zelândia (NZ), EUA e "resto do mundo" - e analisaram as interações entre as políticas nacionais de laticínios e seus efeitos nas quantidades negociadas e nos preços no mercado internacional. 
O principal objetivo da pesquisa foi ampliar a compreensão sobre as interações entre as políticas domésticas de lácteos nos principais países exportadores e seus efeitos sobre as quantidades comercializadas e os preços nos mercados mundiais. Dois experimentos políticos foram conduzidos, nos quais foram feitas mudanças unilaterais nas funções de resposta da política, explicando o estabelecimento dos preços de intervenção domésticos na Comunidade Europeia e nos Estados Unidos. Os resultados sugerem que as políticas comerciais domésticas afetam sensivelmente o preço mundial. No geral, os potenciais beneficiários da intervenção são os produtores domésticos de leite e os consumidores no resto do mundo.

Ainda segundo o ensaio, a maioria dos países desenvolvidos possui indústrias de laticínios bem desenvolvidas e capazes de satisfazer as necessidades domésticas de leite fluido. O custo da intervenção é sustentado, principalmente, pelos consumidores domésticos e pelos contribuintes, sendo que o preço mundial, no entanto, é bastante sensível a mudanças nas políticas domésticas e isto envolve implicações para todos os países que comercializam produtos lácteos. Além do mais, as variações no valor mínimo de suporte ${ }^{2}$ dos EUA parecem estar associadas a mudanças iguais no preço mundial real na direção oposta, sendo a CE responsável apenas pela metade da influência. Tal resultado indica para um excesso de sensibilidade da oferta dos EUA em relação ao preço mínimo de suporte.

Como exemplo, a sensibilidade do preço mundial ligado às variações de preço nos EUA sugere a necessidade de liberalização das políticas de produtos lácteos na $\mathrm{CE}$ e nos EUA, o que aumentaria a competitividade das indústrias de laticínios em outros países, reduzindo a necessidade de intervenção nas políticas. Além disso, tais ganhos fluiriam da redução nos excedentes de exportação na CE e nos EUA, sem qualquer mudança nas importações pelos dois.

Utilizando abordagem metodológica distinta, Ohlan (2014) estimou, por intermédio de um modelo de regressão do tipo log-linear, o impacto da entrada em vigor do regime da OMC - ou seja, antes e após 1995 - sobre a taxa de crescimento anual das exportações mundiais de laticínios, tanto em volume quanto em valor exportado, em termos mundiais e dos dez maiores países produtores, para o período compreendido entre 1980 e 2010.

Como resultado, o autor demonstra que a taxa de crescimento mundial do volume exportado se eleva após 1995, o mesmo não podendo ser concluído para a

${ }^{2}$ Preço mínimo definido pelo governo estadunidense para o leite utilizado na indústria no âmbito do Dairy Price Support Program (KAISER, 1994). trajetória de crescimento do valor exportado, variável que não apresentou significância estatística para o conjunto de dados considerado. Outra observação importante se refere ao fato que produtores responsáveis por grandes volumes de exportação de laticínios, entre eles Holanda, Bélgica, Itália e EUA, experimentaram declínio pronunciado em suas respectivas taxas de crescimento do valor de exportação de laticínio, quando considerado o lapso temporal após a ratificação da OMC (de 1995 até 2010).

Em síntese, as pesquisas citadas averiguaram a atuação tanto de organismos internacionais quanto de políticas públicas internas no tratamento de barreiras comerciais com vistas à determinação das exportações mundiais e regionais de laticínios, apontando para uma relativa ineficácia da $\mathrm{OMC}$ em liberalizar o comércio internacional de lácteos. Particularmente, os ensaios mostraram as consequências das altas tarifas alfandegárias e outras restrições ao comércio de lácteos e os caminhos que podem ser tomados para a liberalização. Com isso, a necessidade de reflexão sobre as políticas comerciais dos países no sentido de se propor uma maior integração econômica no mercado de laticínios permanece constituindo tema de elevado interesse político e acadêmico.

Todavia, rara atenção tem sido dedicada ao estudo do desempenho específico das exportações brasileiras de laticínios frente à complexidade do ambiente regulatório tal como descrito. Neste sentido, a presente investigação buscará oferecer como contribuição para a literatura o diferencial analítico do uso de modelos gravitacionais que intentem calcular em que medida a implantação de práticas protecionistas levadas a cabo pelos principais importadores de produtos lácteos do Brasil é capaz de afetar o desempenho das exportações nacionais. Aliado a isso, como é tradicional em estudos que empregam o mesmo instrumental, o emprego de variáveis de controle potencialmente determinantes do fluxo de exportações permitirá avaliar um quadro mais completo da relação funcional existente entre os elementos aqui considerados.

\section{METODOLOGIA}

Desde o trabalho fundamental de Tinbergen (1962), uma forma tradicionalmente empregada para investigar questões relacionadas a fluxos de comércio internacional e seus determinantes vem a ser o uso de modelos denominados gravitacionais [ver, entre outros, Martin-Mayoral e Jaramillo (2008), Wang, Wei e Liu (2010) e Arevalo, Andrade e Silva (2016)] que, apesar de críticas iniciais apontarem como apartados do devido suporte das teorias do comércio

Organizações Rurais \& Agroindustriais, Lavras, v. 21, n. 1-3, p. 131-147, 2019 
internacional, esforços posteriores, como os de Bergstrand (1985, 1989), demonstraram que os mesmos decorrem diretamente do já citado arcabouço de Krugman (1980).

Conceitualmente semelhantes à teoria da gravitação universal de Isaac Newton, cujo enunciado principal afirma que a força de atração entre dois corpos é diretamente proporcional às suas massas e inversamente proporcional ao quadrado da distância entre seus centros de atração, as equações gravitacionais em economia se valem tanto dos níveis de renda entre as nações comerciantes (que representam as "massas econômicas", neste caso) quanto seus distanciamentos para o comércio, visando adaptar o conceito da Física ao raciocínio econômico (LINDERS; DE GROOT, 2006).

$\mathrm{Na}$ prática, a relação funcional que se pretende definir é a que segue:

$X_{i, j}=\beta_{0} \frac{Y_{i}^{\beta_{2}} Y_{j}^{\beta_{3}}}{D_{i, j}^{\beta_{4}}}$,

em que $\beta_{0}, \beta_{2}, \beta_{3}$ e $\beta_{4}$ são parâmetros desconhecidos, $X_{i j}$ representa as exportações do país $i$ com destino ao país $j$, $Y_{i}$ e $Y_{j}$ são as respectivas rendas per capita e $D_{i, j}$ representa uma medida de determinação do grau de resistência distanciamento - para o comércio entre os países $i$ e $j$.

Contudo, longe da relação determinística que pode ser encontrada nos cálculos das Ciências Exatas, os dados econômicos reais representam, via de regra, fenômenos aleatórios que acarretam a necessidade de uma especificação na forma estocástica para a expressão descrita em (1). Isto é:

$X_{i, j}=\beta_{0} \frac{Y_{i}^{\beta_{2}} Y_{j}^{\beta_{3}}}{D_{i, j}^{\beta_{4}}} \theta_{i, j}$,

onde $\theta_{i, j}$ corresponde a um fator de desvio e $E\left[\theta i, j \mid Y_{i}, Y_{j,} D_{i, j}\right]=1$, assegurando, com isso, que o valor esperado de (2) seja igual à equação (1) (SILVA; TENREYRO, 2006).

Adiante, procurando adaptar a forma multiplicativa prevista em (2) para uma versão compatível com modelos lineares, a extração dos logaritmos naturais em ambos os lados da expressão permite estabelecer a seguinte relação funcional:

$\ln X_{i, j}=\beta_{1}+\beta_{2} \ln Y_{i}+\beta_{3} \ln Y_{j}-\beta_{4} \ln D_{i, j}+e_{i, j}$,

em que $\beta_{1}=\ln \beta^{0}, e_{i, j}=\ln \theta_{i, j}$ e cuja estimação dos parâmetros admite o método habitual de Mínimos Quadrados Ordinários (MQO).
Entretanto, um problema que pode surgir com a versão log-log do modelo gravitacional é a recorrência de valores nulos para $X_{i, j}$. Com efeito, este é o caso para grande parte da realidade do comércio bilateral observado no mundo real, sendo que quando dois países não transacionam entre si, no todo ou para algum conjunto de mercadorias sob investigação, $X_{i, j}$ assume o valor zero, tornando o logaritmo da variável de resposta indefinido.

Para contornar esta dificuldade, autores como Burger, Van Oort e Linders (2009) e Metulini, Patuelli e Griffith (2018) propõem a estimação dos parâmetros com base em modelos de contagem a partir de distribuições de probabilidade não binomiais e de Poisson. Como resultado, a estimação do modelo considerado pode ser feita com a variável dependente expressa em nível, de modo a evitar a perda de informações importantes que adviriam de transformações não justificadas dos valores nulos de $X_{i, j}$ (desconsideração dessas observações ou atribuição de valores aleatórios, como $\$ 1$, por exemplo).

Adicionalmente, para conjuntos de dados que apresentam frequência excessiva de zeros recomendase a utilização de modelos denominados zero-inflados, no intuito de identificar possíveis processos distintos de geração dos valores observados, uma vez que os fenômenos que geram tanto valores nulos quanto positivos podem ser diferentes daqueles que apresentam apenas valores iguais a zero, alterando, com isso, o processo gerador de dados subjacente a cada tipo.

Isto posto, considerando as distribuições de probabilidade expressas pelas fórmulas:

$\operatorname{Prob}_{P}=\operatorname{Pr}\left[X_{i, j}\right]=\frac{e^{-\mu_{i, j}} \mu_{i, j}^{X_{i, j}}}{X_{i, j} !} X_{i, j}=0,1 \ldots$,

para descrever a distribuição de probabilidade de Poisson.

$\operatorname{Prob}_{N B}=\operatorname{Pr}\left[X_{i, j}\right]=\frac{\Gamma\left(X_{i, j}+\alpha^{-1}\right)}{X_{i, j} \Gamma\left(\alpha^{-1}\right)}\left(\frac{\alpha^{-1}}{\alpha^{-1}+\mu_{i, j}}\right)^{\alpha-1} \cdot\left(\frac{\mu_{i, j}}{\alpha^{-1}+\mu_{i, j}}\right)^{X_{i, j}}$
$X_{i, j}=0,1 \ldots$

para o caso não binomial, em que $\Gamma$ representa a função gama e é o parâmetro que captura o grau de sobredispersão.

Ajustificativa para se calcular ambos os modelos reside na sensibilidade da distribuição de Poisson a ruídos causados por problemas de sobredispersão (média condicional menor do que a variância condicional) e heterocedasticidade da variável dependente (NHUONG; WILSON; HITE, 2012). Além 
disso, para casos em que os valores iguais a zero possam ser excessivos e gerados por processos distintos ("zero provável" e "zero certo"), podemos expressar os modelos nas formas ditas não binomial zero-inflado (ZINB) e Poisson zero-inflado (ZIP), como segue:

Modelo ZINB:

$\operatorname{Pr}\left(X_{i, j}=0\right)=p_{i, j}+\left(1-p_{i, j}\right) \cdot\left(\frac{\alpha^{-1}}{\alpha^{-1}+\mu_{i, j}}\right)^{\alpha^{-1}}$,

para os valores zerados de $X_{i, j}$, e

$\operatorname{Pr}\left(X_{i, j}=x\right)=\left(1-p_{i, j}\right) \cdot \operatorname{Prob}_{N B} x>0$,

para valores maiores do que zero. Finalmente, o modelo ZIP pode ser assim determinado:

$\operatorname{Pr}\left(X_{i, j}=0\right)=p_{i, j}+\left(1-p_{i, j}\right) e^{-\mu_{i, j}}$,

para casos análogos a (6), e

$\operatorname{Pr}\left(X_{i, j}=x\right)=\left(1-p_{i, j}\right) \cdot \operatorname{Prob}_{P} x>0$,

se $X_{i, j}$ assumir valores não nulos.

Assim sendo, tais medidas de ajustamento, diante das especificidades de estimação, sugerem a utilização de uma nova relação gravitacional multiplicativa representada pela seguinte função exponencial para a esperança matemática dos valores de $X_{i, j}$ :

$\mu_{i, j}=E\left[X_{i, j} \mid Y_{i}, Y_{j}, D_{i, j}\right]=\exp \left(\beta_{1}+\beta_{2} \ln Y_{i}+\right.$

$+\beta_{3} \ln Y_{j}+\beta_{4} \ln D_{i, j}+\beta_{5} Z_{j}+e_{i, j}$ )

em que $Z_{j}$ assume valores binários de um conjunto de variáveis categóricas e $X_{i, j}$ representa os níveis de exportação, e não mais os logaritmos, distribuídos de acordo com as funções de probabilidade assumidas para cada caso.

Nestas circunstâncias, uma característica importante da especificação dada por (10) vem a ser a necessidade de interpretação dos coeficientes estimados considerando a forma (logaritmo ou nível) como as covariáveis são inseridas na equação ${ }^{3}$ (WOOLDRIDGE, 2010; KRISZTIN;

${ }^{3}$ Conforme os autores, para expressões cuja estrutura tem a forma definida em (10), a elasticidade é constante e igual a $\beta$, para variáveis em log, e semi-elasticidade dada por $[\exp (\beta)-1] .100$, para variáveis em nível. Essas distinções são importantes para a interpretação dos resultados.
FISCHER, 2015). Sendo assim, as discussões a respeito dos resultados obtidos poderão ser desenvolvidas valendo-se desta propriedade.

Diante disso, a presente análise considerou o conjunto de produtos classificados pelo HS compreendidos nas posições de 0401 a 0406 , que representa, grosso modo, as seguintes mercadorias: leite e creme de leite, não concentrados nem adicionados de açúcar ou de outros edulcorantes; leite e creme de leite, concentrados ou adicionados de açúcar ou de outros edulcorantes; leitelho, leite e creme de leite coalhados, iogurte, quefir e outros leites e cremes de leite fermentados ou acidificados, mesmo concentrados ou adicionados de açúcar ou de outros edulcorantes, ou aromatizados ou adicionados de frutas ou de cacau; soro de leite, mesmo concentrado ou adicionado de açúcar ou de outros edulcorantes; produtos constituídos por componentes naturais do leite, mesmo adicionados de açúcar ou de outros edulcorantes; manteiga e outras matérias gordas provenientes do leite; pasta de espalhar de produtos provenientes do leite; e queijos e requeijão.

Para melhor exposição das variáveis envolvidas na investigação, a Quadro 1 sumariza o descritivo, as referências bibliográficas e os sinais esperados na relação com a variável explicada (SIQUEIRA, LINHARES, HOTT, 2011; KAREEM, MARTINEZ-ZARZOSO, BRÜMMER, 2016; NHUONG; WILSON, HITE, 2012; DLAMINI et al., 2016):

Todos os dados referentes aos valores de exportação foram extraídos do sistema Comexstat, vinculado ao Ministério da Economia, e foram deflacionados para valores reais de 2010 pela série "Exportações - setor: produtos alimentícios - preços - índice”, disponível no sítio eletrônico do Instituto de Pesquisa Econômica Aplicada. Além desses, as variáveis de renda nacional real (ano base 2010) foram obtidas na página eletrônica do Banco Mundial. No que se refere às tarifas percentuais em equivalente ad valorem, a instituição provedora dos dados é a OMC, em seu repositório disponível na internet.

A justificativa para o uso desta variável é que a mesma transforma cotas, subsídios e todos os outros instrumentos de proteção comercial em um único indicador, permitindo a comparação entre os países e as mercadorias (SIQUEIRA, LINHARES E HOTT, 2011).

Por fim, os dados que compõem os indicadores de resistência ao comércio, sendo eles: distância geográfica (em quilômetros) entre o Brasil e o respectivo parceiro comercial, as variáveis categóricas (dummies) para "fronteira compartilhada", "ausência de litoral", "pertence ao Mercosul" e "português é a língua oficial" provêm da base de dados do "Centre d'Etudes Prospectives et d'Informations Internationales" (CEPII). 


\section{RESULTADOS E DISCUSSÕES}

Caberá a este tópico apresentar os resultados apurados pela pesquisa. Neste sentido, serão introduzidas as estatísticas descritivas para que, na sequência, a tabela de correlações entre as variáveis preceda a exposição dos modelos estimados de acordo com a metodologia proposta. Inicialmente, na Tabela 1 podem ser visualizadas as informações sumárias básicas das grandezas envolvidas na análise:

QUADRO 1 - Descritivo e sinais esperados das variáveis

\begin{tabular}{|clc|}
\hline Mnemônico & \multicolumn{1}{c}{ Descrição } & Sinal esperado \\
\hline In_eav & Logaritmo do indicador de barreira tarifária em equivalente ad valorem (na forma 1+taxa) ${ }^{4}$. & Negativo \\
In_gdp & Logaritmo da renda interna real do importador em valores reais. & Positivo \\
In_gdpbr & Logaritmo da renda interna brasileira em valores reais. & Negativo \\
ln_rer & Logaritmo da taxa real de câmbio efetiva ${ }^{5}$ & Positivo \\
ln_dist & Logaritmo da distância geográfica. & Negativo \\
contig & Compartilha fronteira geográfica. 1: sim; 0: não. & Positivo \\
landlocked & Ausência de litoral. 1: sim; 0: não. & Negativo \\
lang & Idioma oficial português. 1: sim; 0: não. & Positivo \\
\hline
\end{tabular}

Fonte: dados da pesquisa

TABELA 1 - Estatísticas descritivas

\begin{tabular}{|c|c|c|c|c|c|c|}
\hline Variável & & Média & Desv.Pad. & Mín & Máx & Obs. \\
\hline \multirow{3}{*}{$\exp (\mathrm{mil})$} & Total & 247,29 & $1.610,27$ & 0,00 & $54.867,46$ & $\mathrm{~N}=3310$ \\
\hline & Entre painéis & & $1.120,16$ & 0,00 & $12.842,69$ & $\mathrm{n}=331$ \\
\hline & Intra painéis & & $1.158,29$ & $-12.595,40$ & $42.272,07$ & $\mathrm{~T}=$ \\
\hline \multirow{3}{*}{ eav } & Total & 1,22 & 0,45 & 1,00 & 5,27 & $\mathrm{~N}=3310$ \\
\hline & Entre painéis & & 0,43 & 1,00 & 3,95 & $\mathrm{n}=331$ \\
\hline & Intra painéis & & 0,14 & $-1,04$ & 2,70 & $\mathrm{~T}=$ \\
\hline \multirow{3}{*}{ gdp (bil) } & Total & 652,45 & $1.422,91$ & 0,30 & $11.140,00$ & $\mathrm{~N}=3310$ \\
\hline & Entre painéis & & $1.373,59$ & 0,40 & $7.758,70$ & $\mathrm{n}=331$ \\
\hline & Intra painéis & & 378,21 & $-3.556,25$ & $4.033,75$ & $\mathrm{~T}=$ \\
\hline \multirow{3}{*}{ gdpbr (bil) } & Total & $2.060,00$ & 410,52 & $1.400,00$ & $2.620,00$ & $\mathrm{~N}=3310$ \\
\hline & Entre painéis & & 0,00 & $2.060,00$ & $2.060,00$ & $\mathrm{n}=331$ \\
\hline & Intra painéis & & 410,52 & $1.400,00$ & $2.620,00$ & $\mathrm{~T}=$ \\
\hline \multirow{3}{*}{ rer } & Total & 112,39 & 16,57 & 85,30 & 138,92 & $\mathrm{~N}=3310$ \\
\hline & Entre painéis & & 0,00 & 112,39 & 112,39 & $\mathrm{n}=331$ \\
\hline & Intra painéis & & 16,57 & 85,30 & 138,92 & $\mathrm{~T}=$ \\
\hline \multirow{3}{*}{ dist (mil) } & Total & 8,15 & 4,29 & 1,55 & 18,70 & $\mathrm{~N}=3310$ \\
\hline & Entre painéis & & 4,29 & 1,55 & 18,70 & $\mathrm{n}=331$ \\
\hline & Intra painéis & & 0,00 & 7,91 & 8,18 & $\mathrm{~T}=$ \\
\hline
\end{tabular}

Fonte: elaborada pelos autores a partir de dados da pesquisa. N: número de observações; i: número de painéis e T: número de períodos Nota: os valores "intra painel" mínimos negativos não são um equívoco. Decorre da variação interna das variáveis em relação aos países e em torno da média global. Ou seja, mínimo "intra painel" $=\left(\boldsymbol{x}_{i t}-\overline{\boldsymbol{x}}_{\boldsymbol{l}}-\overline{\boldsymbol{x}}_{\boldsymbol{i t}}\right)$

${ }^{4}$ Isto é, inclui as tarifas não expressas em termos percentuais (a exemplo dos impostos de montante fixo) devidamente convertidas para suas taxas percentuais correspondentes.

${ }^{5} \mathrm{~A}$ taxa de câmbio real efetiva pode ser calculada pela fórmula: rer=(E. $\left.P^{*} . i\right) / P$, em que $E$ corresponde à taxa de câmbio nominal, $P^{*}$ e $P$ são os respectivos níveis de preços internacionais e domésticos e $i$ é o ponderador que ajusta o peso relativo de cada parceiro comercial no total de exportações. 
De acordo com as estatísticas dispostas na Tabela 1, os dados mais importantes para a compreensão dos valores das variáveis sugerem o seguinte: com relação à magnitude das exportações anuais correntes, variável (x), a média total observada foi de 247 mil dólares quando consideradas todas as dimensões do painel. Em específico, o valor máximo de exportações observado foi de 54.867 mil dólares no ano de 2007 e teve como destino a Argélia, no Norte da África.

Com respeito às barreiras tarifárias representadas pela variável (eav), o que vem demonstrado é uma média correspondente a 22 p.p. em equivalente ad valorem. $\mathrm{O}$ valor máximo neste quesito foi de $427 \%$ cobrados pela Noruega, cobrados anualmente entre 2012 e 2016. É digno de nota que um país reconhecidamente desenvolvido e de elevado pib per capita mantenha as elevadas barreiras tarifárias para as exportações lácteas brasileiras.

Prosseguindo, para os produtos internos brutos dos países de destino das exportações, variável $(g d p)$, a média observada foi de 652 bilhões de dólares considerando todas as dimensões do painel. Mais detidamente, o valor mínimo observado foi de US\$ 300 bilhões referentes a Tonga, na Oceania, no ano de 2007, e o valor máximo foi de US\$ 11.140 bilhões para a China, em 2016. Com isso, percebe-se uma destacada heterogeneidade nos parceiros comerciais, visto que agrega desde países de reduzida renda bruta, como no caso de Tonga, até grandes potências econômicas como China e Estados Unidos.

Relativamente ao PIB brasileiro ( $g d p b r)$, a média apresentada foi de 2.060 bilhões de dólares. $\mathrm{O}$ valor mínimo foi de 1.400 bilhões de dólares e o valor máximo foi de US\$ 2.620 bilhões. Esses valores refletem um período de bom desempenho na economia do país, que com exceção do ano de 2009, com ganhos generalizados em diversos setores econômicos, incluindo a agropecuária e a agroindústria.

Por fim, a distância média apurada entre o Brasil e seus parceiros comerciais da amostra foi de $8 \mathrm{mil} \mathrm{km}$, sendo que o valor mínimo de 1,5 mil $\mathrm{km}$ reflete a extensão geográfica até o Paraguai e a distância máxima de 18,6 mil km refere-se à distância entre o Brasil e as Filipinas, na Ásia. A grande variação nas distâncias mostra o caráter amplo e diverso presente nas relações comerciais que o país possui com diversos países de todos os continentes, reforçando, dessa forma, a relevância que tais disparidades de valores podem ter sobre os custos de frete e, por consequência, no desempenho das exportações.

Adiante, a Tabela 2 reproduz as magnitudes de correlação associadas às suas respectivas significâncias estatísticas:

Com exceção do valor atribuído às variáveis rer $\mathrm{e}$ gdpbr (-0,952), o conteúdo disposto na tabela denota níveis aceitáveis de correlações no sentido de evitar os efeitos provocados por graus elevados de multicolinearidade.

Em vista disso, procederemos, com base nos dados da Tabela 3 abaixo, à exposição dos resultados encontrados para que, na sequência, os fenômenos sugeridos pelos valores calculados possam ser devidamente discutidos com o devido apoio da literatura existente.

Assim como analisado, o esforço de investigação consistirá da estimação de quatro modelos distintos, sendo dois deles, PPML e NB, utilizados para tratar a ocorrência de observações iguais a zero, e os demais, ZIP e ZINB para lidar com a possível contagem excessiva desses valores.

TABELA 2 - Correlações

\begin{tabular}{|c|c|c|c|c|c|c|c|c|c|}
\hline Variáveis & (1) & (2) & (3) & (4) & (5) & (6) & (7) & (8) & (9) \\
\hline (1) $\exp$ & 1,000 & & & & & & & & \\
\hline (2) $e a v$ & $-0,034^{* *}$ & 1,000 & & & & & & & \\
\hline (3) $g d p$ & $-0,039^{* *}$ & $0,095^{* *}$ & 1,000 & & & & & & \\
\hline (4) $g d p b r$ & $0,042^{* *}$ & 0,016 & $0,140^{* *}$ & 1,000 & & & & & \\
\hline (5) rer & $-0,056^{* *}$ & $-0,018$ & $-0,134^{* *}$ & $-0,952^{* *}$ & 1,000 & & & & \\
\hline (6) dist & $-0,040^{* *}$ & 0,019 & $0,390^{* *}$ & $-0,000$ & 0,000 & 1,000 & & & \\
\hline (7) contig & 0,022 & $-0,053^{* *}$ & $-0,121^{* *}$ & $-0,000$ & $-0,000$ & $-0,467^{* *}$ & 1,000 & & \\
\hline (8) landlocked & $-0,003$ & $0,105^{* *}$ & $-0,078^{* *}$ & $-0,000$ & $-0,000$ & $-0,118^{* *}$ & $0,136^{* *}$ & 1,000 & \\
\hline (9) lang & $0,061^{* *}$ & $-0,089^{* *}$ & $-0,097^{* *}$ & $-0,000$ & $-0,000$ & $-0,116^{* *}$ & $-0,093^{* *}$ & $-0,066^{* *}$ & 1,000 \\
\hline
\end{tabular}

** $\mathrm{p}<0,05$.

Fonte: elaborada pelos autores a partir de dados da pesquisa

Organizações Rurais \& Agroindustriais, Lavras, v. 21, n. 1-3, p. 131-147, 2019 
TABELA 3 - Resultados apurados (variável dependente: valor corrente das exportações, em mil - exp)

\begin{tabular}{|c|c|c|c|c|c|c|}
\hline \multirow{2}{*}{$\begin{array}{c}\text { Variável } \\
\text { explicativa }\end{array}$} & \multirow[b]{2}{*}{$\begin{array}{c}\text { ppml } \\
\text { (1) }\end{array}$} & \multirow[b]{2}{*}{$\begin{array}{l}\text { nb } \\
(2)\end{array}$} & \multicolumn{2}{|c|}{ zip } & \multicolumn{2}{|c|}{ zinb } \\
\hline & & & $\begin{array}{l}\text { padrão } \\
\text { (3) }\end{array}$ & $\begin{array}{c}\text { zero-inflado } \\
\text { (4) }\end{array}$ & $\begin{array}{l}\text { padrão } \\
\text { (5) }\end{array}$ & $\begin{array}{c}\text { zero-inflado } \\
\text { (6) }\end{array}$ \\
\hline \multirow[t]{2}{*}{ In_eav } & $-1,252$ & $-0,905^{* * *}$ & $-2,809^{* * *}$ & $0,633^{* *}$ & $-4,303^{* * *}$ & 0,352 \\
\hline & $(1,593)$ & $(0,330)$ & $(0,763)$ & $(0,322)$ & $(0,693)$ & $(0,380)$ \\
\hline \multirow[t]{2}{*}{ In_gdp } & 0,341 & $0,140^{* * *}$ & $0,264^{* * *}$ & $-0,163^{* * *}$ & $0,650^{* * *}$ & $-0,116^{* *}$ \\
\hline & $(0,585)$ & $(0,035)$ & $(0,034)$ & $(0,034)$ & $(0,087)$ & $(0,046)$ \\
\hline \multirow[t]{2}{*}{ In_gdpbr } & $-3,194^{* *}$ & $-5,890^{* * *}$ & $-0,970$ & $5,316^{* * *}$ & $-3,177^{* * *}$ & $5,283^{* * *}$ \\
\hline & $(1,307)$ & $(0,524)$ & $(1,311)$ & $(0,753)$ & $(1,059)$ & $(0,843)$ \\
\hline \multirow[t]{2}{*}{ In_dist } & $-0,998$ & $-0,971^{* * *}$ & $-0,778^{* * *}$ & $0,995^{* * *}$ & $-1,328^{* * *}$ & $0,880^{* * *}$ \\
\hline & $(1,168)$ & $(0,202)$ & $(0,167)$ & $(0,187)$ & $(0,249)$ & $(0,216)$ \\
\hline \multirow[t]{2}{*}{ In_rer } & $-2,834^{* *}$ & $-5,581^{* * *}$ & $-0,803$ & $4,792^{* * *}$ & $-3,066^{* *}$ & $4,762^{* * *}$ \\
\hline & $(1,172)$ & $(0,735)$ & $(1,526)$ & $(1,008)$ & $(1,402)$ & $(1,108)$ \\
\hline \multirow[t]{2}{*}{ contig } & 0,181 & $1,112^{* * *}$ & $-0,640^{* * *}$ & $-1,629^{* * *}$ & $-1,790^{* * *}$ & $-3,484$ \\
\hline & $(1,904)$ & $(0,263)$ & $(0,235)$ & $(0,413)$ & $(0,405)$ & $(2,948)$ \\
\hline \multirow[t]{2}{*}{ landlocked } & $-1,128$ & $-1,122^{* * *}$ & 0,143 & $0,734^{* * *}$ & 0,459 & $0,953^{* * *}$ \\
\hline & $(0,904)$ & $(0,278)$ & $(0,216)$ & $(0,232)$ & $(0,314)$ & $(0,301)$ \\
\hline \multirow[t]{2}{*}{ lang } & 1,065 & 0,313 & $1,001^{* * * *}$ & $-0,798^{* *}$ & 0,399 & $-0,867^{* *}$ \\
\hline & $(0,916)$ & $(0,265)$ & $(0,274)$ & $(0,325)$ & $(0,307)$ & $(0,385)$ \\
\hline \multirow[t]{2}{*}{ Constante } & $71,354^{* * *}$ & $116,901^{* * *}$ & 29,537 & $-106,452^{* * *}$ & $72,952^{* * *}$ & $-105,485^{* * *}$ \\
\hline & $(27,391)$ & $(11,084)$ & $(26,080)$ & $(15,547)$ & $(21,700)$ & $(17,349)$ \\
\hline $\mathbf{N}$ & 1040 & 860 & & & & \\
\hline \multicolumn{3}{|l|}{ N(zeros) } & & & \multicolumn{2}{|c|}{1040} \\
\hline Pseudolikelihood & $-318068,603$ & $-2924,989$ & \multicolumn{2}{|c|}{1040} & \\
\hline AIC & 636157,206 & 5867,978 & \multicolumn{2}{|c|}{619} & \multicolumn{2}{|c|}{$-3877,703$} \\
\hline BIC & 636206,676 & 5910,790 & \multicolumn{2}{|c|}{1651503,019} & \multicolumn{2}{|c|}{7887,399} \\
\hline Vuong() & & & \multicolumn{2}{|c|}{1651592,064} & \multicolumn{2}{|c|}{8,755} \\
\hline \multirow{2}{*}{\multicolumn{3}{|c|}{ Vuong(prob.) }} & & & & \\
\hline & & & & & & \\
\hline Sobredisp.() & 1,713 & & & & & \\
\hline Sobredisp(e.p.) & $(1,281)$ & & & & & \\
\hline Efeitos fixos & Não & Sim & & & & \\
\hline
\end{tabular}

$* \mathrm{p}<0,10, * * \mathrm{p}<0,05, * * * \mathrm{p}<0,010$. Erro-padrão entre parênteses. ${ }^{+}$Significativo em todos os modelos. ${ }^{\S}$ Efeitos fixos não assumidos por questão de convergência do modelo. a: Pseudo-máxima verossimilhança para distribuições de Poisson. b: Poisson zero-inflado. c: Binomial negativa. d: Não binomial zero-inflado. Foram calculados erros-padrão robustos para as estimações

Fonte: resultados da pesquisa

Para definição do modelo mais adequado, segundo as melhores práticas encontradas na literatura, seguiu-se a recomendação de Zaninotto e Falaschetti (2011) e Nhuong, Wilson e Hite (2012). Para tanto, os valores do teste de Vuong, utilizado para selecionar entre modelos ZIP/ZINB e seus correspondentes-padrão PPML/NB (VUONG,
1989), de cujos valores positivos e estatisticamente significativos atribuídos aos modelos zero-inflados, apontam para adequação destes em detrimento dos modelos PPML e NB. Além disso, a presença de resultado significativo e maior que a unidade para o coeficiente (equivalente a 1,28 ) evidencia a presença de sobredispersão dos dados, 
fato que, aliado às menores magnitudes dos critérios de informação (AIC/BIC) do modelo ZINB, leva a decidir-se por esta especificação entre as anteriormente selecionadas.

De resto, o cômputo robusto dos erros-padrão, aliado ao comportamento satisfatório dos valores retornados, permitem inferir que, além da consistência diante de possível heterocedasticidade, a alta correlação identificada na Tabela 2 parece não produzir multicolinearidade capaz de comprometer os resultados (GOLDBERGER, 1991). Desta maneira, em vista do modelo assumido, as colunas (5) e (6) da Tabela 3 servirão de subsídio à exposição subsequente.

Conforme discutido na seção de metodologia precedente, modelos zero-inflados admitem distribuições distintas para caracterização dos valores observados. Em um primeiro caso, as contagens de zero são representadas pela distribuição do tipo logit, coluna (6), ao passo que os valores não nulos seguem uma distribuição padrão não binomial [coluna (5)]. Sendo assim, a interpretação dos resultados pode ser feita de forma conjunta, observando como cada variável pode, concomitantemente, impactar valores não nulos da variável de resposta, ou, de maneira probabilística, indicar quais são as chances dessa mesma variável anular (zerar) o comércio bilateral de laticínios.

A princípio, as variáveis correspondentes às barreiras tarifárias ( $\left.l n \_e a v\right)$, renda externa ( $\left.l n \_g d p\right)$, bem como a distância geográfica (ln_dist) se apresentaram tanto estatisticamente diferentes de zero quanto exibiram o sinal esperado para a relação funcional, em todos os modelos considerados [colunas (1) a (4)] na Tabela 3. Já a variável (ln_rer) apresentou significância estatística em três modelos - ppml, nb e zinb -, (contig), por sua vez, foi significativa nos modelos não binomiais (nb e zinb). A variável (landlocked) se mostrou significativa apenas para o modelo nb e, finalmente, (lang) não reportou significância estatística.

Conforme discutido, a metodologia adotada neste trabalho exige a interpretação dos coeficientes apurados observando a natureza dos valores de entrada, log ou nível, em relação à variável dependente. Desta forma, a Tabela 3 fornece os valores dos coeficientes devidamente transformados e com valores de sensibilidade calculados considerando a média da variável explicativa; além de reportar as informações equivalentes para o componente zero-inflado da equação estimada.

Neste sentido, levando em conta os valores dispostos na tabela, quando o nível da tarifa equivalente ad valorem eleva-se em 1\%, variável (ln_eav), a queda no volume exportado, tudo o mais constante, pode chegar a $4,30 \%$, resultado em linha com o ensaio de Sanjuan et al. (2017).
Em raciocínio similar, pode-se verificar que, dado o mesmo estado de coisas, na ocasião de aumentos de $1 \%$ na renda mundial ( $\left.l n \_g d p\right)$, a quantidade exportada pode aumentar, em média, 0,65\%. Ainda sobre variações de renda, a variável ( $\ln \_g d p b r$ ), representativa do produto $p e r$ capita interno, retornou a grandeza de $-3,17$, implicando que, no caso de aumento de $10 \%$ na renda interna, as exportações nacionais de laticínios podem cair algo próximo de $32 \%$, indo de encontro aos resultados apurados por da Silva, Ferreira e de Lima (2015).

Além desse fato, constata-se que elevações de $10 \%$ nas distâncias geográficas dos parceiros comerciais reduz, em média, os valores de exportação na proporção 13,28\%, concordando com investigações como as de Cheng e Wall (2005) e Brun et al (2005), por exemplo.

Em oposição ao preconizado pela literatura do tema, o resultado negativo para a variável (ln_rer) aponta que alterações de $1 \%$ na taxa real de câmbio efetiva provocam reduções nos valores exportações na magnitude de 3,07\%, em média. Em rigor, tal evento, conhecido como Condição Marshall-Lerner, postula que desvalorizações cambiais aprimoram a situação em conta corrente de um país somente se o somatório das elasticidades-renda da demanda por importações e por exportações for maior que um (BRAGA; OLIVEIRA, 2018).

Neste ponto, evidências semelhantes podem ser encontradas nas investigações realizadas por Dlamini et al. (2016) e Brun et al. (2005). Considerando que a taxa real de câmbio expressa o nível de competitividade dos setores de bens transacionáveis, equalizando, dessa forma, os preços nacionais e do exterior, corrigidos pela respectiva taxa nominal de câmbio (LOCATELLI; DA SILVA, 1991), elevações da taxa expressam uma depreciação da moeda do país importador vis-à-vis a do país exportador, deprimindo as importações (BRUN, et al. 2005).

Por fim, contrariamente a trabalhos anteriores com abordagens semelhantes (GRANT, LAMBERT, 2005; MOORE, 2018; RIBEIRO, FERRO, 2017, entre outros) os valores atribuídos às variáveis binárias (landlocked) e (lang) correspondentes à ausência de litoral e o português como idioma oficial, respectivamente, não alcançaram coeficientes estatisticamente significativos, o que compele a rejeitar as hipóteses de relevância dessas características geográficas e culturais para o desempenho das exportações. Exceção se faz à variável (contig), cujo significado é o compartilhamento de fronteira, apresentou semi-elasticidade inesperada de $-83,3 \%$ [(exp(-1,79)-1).100], indicando que a existência de fronteira política comum pode significar níveis de exportações até $83 \%$ menores que na situação oposta. 
De forma complementar, a coluna de coeficientes estimados para a probabilidade de nenhum comércio reporta que aumentos de $1 \%$ na renda do parceiro comercial diminuem a chance de volume de exportação igual a zero em $0,12 \%$. Em raciocínio semelhante, para elevações de $1 \%$ na renda nacional, a probabilidade esperada de zero comércio aumenta em 5,28\%. Para o caso da distância geográfica, a mesma elevação percentual aumenta a chance de comércio nulo em $0,88 \%$. Na sequência, valorizações de $1 \%$ no câmbio real aumentam em até $4,76 \%$ a chance de não exportar para um dado parceiro.

Por fim, as variáveis categóricas para ausência de litoral e de idioma em comum, isto é, quando a primeira assume valor igual a 1 e a segunda 0 , aumentam em $159,35 \%$ [(exp(0,953)-1).100] e 57,98\% [(exp(-0,867)-1).100], respectivamente, a probabilidade de comércio bilateral de laticínios com valores nulos. Resta relevante destacar que não foram encontradas evidências de significância estatística para a capacidade da tarifa em equivalente ad valorem em determinar ausência absoluta de comércio, ou seja, ainda que haja papel importante na redução do comércio, pode-se inferir que a mesma não possui potencial proibitivo para as exportações lácteas brasileiras.

Diante de todo o exposto, caberá ao próximo tópico apresentar as sínteses conclusivas e demais discussões pertinentes.

\section{CONCLUSÕES}

No Brasil, diversos problemas relacionados à produção de laticínios ocasionam um cenário com excesso de oferta desses produtos no mercado. Pecuaristas e industriários se queixam dos custos de produção e dos impostos que prejudicam a concorrência no setor, apontando a necessidade de desonerar a cadeia produtiva para que os preços fiquem mais competitivos.

A robusta significância estatística de alguns dos resultados encontrados neste trabalho sugere que um caminho possível para alavancar os resultados externos do setor reside nos esforços de remoção das restrições às exportações brasileiras junto às organizações competentes, na identificação de ciclos de crescimento da economia mundial e na correta gestão logística e de transporte, uma vez que, provavelmente, o custo de transporte tem exercido forte pressão sobre o desempenho exportador. Não só nestes quesitos, a influência da política cambial e as condições do produto interno do país, apesar de menos significativas do ponto de vista do conjunto dos modelos calculados, indicam que a política econômica doméstica constitui elemento de relevante contribuição para o segmento.
Para além dos cenários políticos e regulatórios aqui tratados, a busca por competividade do setor de laticínios envolve fatores que abarcam desde os sistemas de produção no campo até o nível de investimentos nos mais avançados desenvolvimentos tecnológicos dos complexos agroindustriais e agroalimentares.

As condições de ambiente relacionadas com a produção de leite não são homogêneas em todos os estados da federação brasileira. Os estados da região Sul do Brasil apresentam condições de clima e produção de forragens - principal alimento do rebanho bovino - relativamente adequadas à criação de raças leiteiras de origem europeia. As forrageiras cultivadas em clima temperado apresentam crescimento mais lento e menor produtividade por unidade de área, se comparadas às forrageiras tropicais. Contudo, apresentam composição de nutrientes (menor teor de fibras, maior teor de energia e proteínas e melhor digestibilidade) mais adequada para a nutrição da vaca leiteira para as mesmas condições de manejo. $\mathrm{O}$ fornecimento de silagens (principalmente de milho, outro item de alimentação) tem sido o procedimento mais comumente adotado, porém de custo mais elevado.

Melhorias nos índices de produtividade de leite em regiões tropicais têm sido obtidas, nos últimos anos, como resultado do cruzamento de bovinos europeus com animais zebuínos de alta linhagem leiteira. Apesar disso, o patamar de produção atingido ainda é bem inferior ao obtido em regiões subtropicais. Em decorrência, a associação desses e outros fatores têm repercutido no custo de produção do litro de leite e conferido vantagens comparativas aos estados do Paraná, Santa Catarina e Rio Grande do Sul, comparativamente a Minas Gerais e Goiás, dentre outros Estados da federação.

$\mathrm{Na}$ outra extremidade da cadeia produtiva, o papel desempenhado pela pesquisa e o desenvolvimento de novos produtos derivados do leite tem estimulado a competição e a conquista de mercados por meio da introdução de artigos portadores de elevado conteúdo tecnológico. Como exemplo, podemos citar a popularização do consumo de alimentos "high tech", entre eles a proteína do soro de leite ou "whey protein", cuja produção envolve tecnologias sofisticadas que conferem ao produto um alto valor agregado.

Em resumo, para que seja possível alavancar os ganhos do setor de laticínios, as informações apresentadas apontam para um conjunto de medidas de políticas públicas que defendam, além da abertura do comércio internacional e da redução de conflitos comerciais, o direcionamento de recursos para o mapeamento das condições de produção e de desenvolvimento tecnológico da atividade. 


\section{REFERÊNCIAS}

ALVIM, A. M. As consequências dos acordos de livre comércio sobre o setor de lácteos no Brasil. Rev. Econ. Sociol. Rural [online]. 2010, Brasília, v. 48, n. 2, p. 405428. Disponível em: http://dx.doi.org/10.1590/S010320032010000200007. Acesso em: 01 jul. 2019.

AREVAlO, J. L. S; ANDRADE, Á. M. F. de; SILVA, G. A. B. Uma nota sobre modelos gravitacionais aplicados à exportação de café de Brasil, Colômbia e Peru. Revista Brasileira de Economia, Rio de Janeiro, v. 70, n. 3, p. 271-280, 2016.

BERGSTRAND, J. H. The generalized gravity equation, monopolistic competition, and the factor-proportions theory in international trade. The review of economics and statistics, Cambridge, v. 71, n. 1, p. 143-153, fev. 1989.

BERGSTRAND, J. H. The gravity equation in international trade: some microeconomic foundations and empirical evidence. The review of economics and statistics, Cambridge,v. 67, n. 3, p. 474-481, ago. 1985.

BRAGA, F. L. P.; OLIVEIRA, A. C. S. de. A Influência da Taxa de Câmbio e Renda Mundial Sobre as Exportações Brasileiras de Soja (2000-2015). Revista de Economia e Sociologia Rural, Brasília, v. 56, n. 4, p. 663-680, 2018.

BROCARD, L. Principes d'économie nationale et internationale. Recueil Sirey (société anonyme), 1929.

BRUN, J. F. et al.. Has distance died? Evidence from a panel gravity model. The World Bank Economic Review, Oxford, v. 19, n. 1, p. 99-120, 2005.

BURGER, M.; VAN OORT, F.; LINDERS, G. On the specification of the gravity model of trade: zeros, excess zeros and zero-inflated estimation. Spatial Economic Analysis, London, v. 4, n. 2, p. 167-190, 2009.

CHENG, I-H.; WALL, H. J. Controlling for heterogeneity in gravity models of trade and integration. Federal Reserve Bank of St. Louis Working Paper Series, Vol. 87, No. 1, pp. 49-63, 2005. Disponível em: http://papers.ssrn.com/sol3/ papers.cfm?abstract_id=656201. Acesso em: 01 jul. 2019.

COUTINHO, E. S. et al. De Smith a Porter: um ensaio sobre as teorias de comércio exterior. REGE Revista de Gestão, São Paulo, v. 12, n. 4, p. 101-113, 2005.
CURRY, A. Archaeology: the milk revolution. Nature News, London, v. 500, n. 7460, p. 20, 2013.

DA SILVA, T. J. J.; FERREIRA, M. O.; DE LIMA, J. R. F. Desempenho exportador da manga e uva brasileira no comércio internacional: uma aplicação com modelo gravitacional. In: Embrapa Semiárido-Artigo em anais de congresso (ALICE). In: CONGRESSO DA SOCIEDADE BRASILEIRA DE ECONOMIA, ADMINISTRAÇÃO E SOCIOLOGIA RURAL, 53, 2015, João Pessoa. Agropecuária, meio ambiente e desenvolvimento: anais. João Pessoa: Sober, 2015., 2015.

DLAMINI, S. G. et al. Determinants of Swaziland's sugar export: a gravity model approach. International Journal of Economics and Finance, Richmond Hill, v. 8, n. 10, p. 71-81, 2016.

EDERINGTON, J.; RUTA, M. N. Measures and the World Trading System. In: Handbook of Commercial Policy. North-Holland, 2016. p. 211-277.

FREITAS, R. E.; COSTA, C. C. Tarifas agrícolas europeias: uma contribuição para sua interpretação. In: CONGRESSO BRASILEIRO DE ECONOMIA E SOCIOLOGIA RURAL, 43., 2005, Ribeirão Preto. Anais... Ribeirão Preto, SP: USP, 2005. 1 CD-ROM.

GEROSA, S.; SKOET, J. Milk availability: Current production and demand and medium term outlook, Chapter 2. Milk and dairy products in human nutrition. Muehlhoff E., Bennett A., McMahon D.(eds), Food and Agriculture Organization of the United Nations, Rome, 2013.

GOLDBERGER, A. S. A course in econometrics. Cambridge, Mass: Harvard University Press, 1991.

GRANT, J. H.; LAMBERT, D. M. Regionalism in world agricultural trade: Lessons from gravity model estimation. 2005.

GRIFFITH, G.; LATTIMORE, R.; ROBERTSON, J. Domestic dairy policies and international market adjustment in a simplified model of world dairy products trade. Journal of Policy Modeling, New York, v. 15, n. 2, p. 141-156, 1993.

HABERLER, G. V. Theory of international trade: With its applications to commercial policy. William Hodge and Company Limited, London, 1936. 
HAUSMANN, R. et al.. Country Diversification, Product Ubiquity, and Economic Divergence. Harvard Kennedy School of Government, 2010.

HAUSMANN, Ricardo; HWANG, Jason; RODRIK, Dani. What you export matters. Journal of economic growth, Providence, v. 12, n. 1, p. 1-25, 2007.

HECKSCHER, E. The effect of foreign trade on the distribution of income". In: BERTIL, O.; HECKSCHER, E. Heckscher-Ohlin trade theory. Cambridge: MIT Press, 1991.

HELPMAN, E. The structure of foreign trade. Journal of Economic Perspectives, Pittsburgh, v. 13, n. 2, p. 121-144, 1999.

INSTITUTO BRASILEIRO DE GEOGRAFIA E ESTATÍSTICA (IBGE). Censo Agropecuário 2017. Pecuária. Resultados preliminares. Brasil, Grandes Regiões e UFs. Brasília/Rio de Janeiro: MPOG, 2018.

KAISER, H. M. An analysis of policy alternatives to the dairy price support program. Agricultural and Resource Economics Review, Cambridge, v. 23, n. 2, p. 158-170, 1994.

KAREEM, F. O.; MARTINEZ-ZARZOSO, I.; BRÜMMER, B. Fitting the gravity model when zero trade flows are frequent: A comparison of estimation techniques using Africa's trade data. Global Food Discussion Paper No. 77. Göttingen: Georg-August University Göttingen.

KRISZTIN, T.; FISCHER, M. M. The gravity model for international trade: Specification and estimation issues. Spatial Economic Analysis, London, v. 10, n. 4, p. 451-470, 2015.

KRUGMAN, P. Scale Economies, Product Differentiation, and the Pattern of Trade. The American Economic Review, Pittsburgh, v. 70, n. 5, p. 950-959, 1980.

LINDERS, G. J. M.; DE GROOT, H. L. F. Estimation of the Gravity Equation in the Presence of Zero Flows. TI Discussion Paper, n. 06-072/3, 2006.

LIST, G. F. Sistema nacional de economia política. São Paulo: Nova Cultural, 1986.
LOCATELli, R. L.; DA SILVA, J. A. B. Câmbio real e competitividade das exportações brasileiras. Revista Brasileira de Economia, Rio de Janeiro, v. 45, n. 4, p. 543-564, 1991.

MARTIN-MAYORAL, F.; JARAMILLO, G. What the Gravity Model of Trade Shows about International Trade Flows in Latin America. Available at SSRN 1370549, 2008.

MESQUITA, P. E. A Organização Mundial do Comércio/ Paulo Estivallet de Mesquita. Brasília: FUNAG, 2013.

METULINI, R.; PATUELLI, R.; GRIFFITH, D. A spatialfiltering zero-inflated approach to the estimation of the gravity model of trade. Econometrics, Basel, v. 6, n. 1, p. 9, 2018.

MILANEZ, A. Y. et al. Desafios para a exportação brasileira de leite. BNDES Setorial, Rio de Janeiro, v. 24, n. 48 , p. [45]-114, set. 2018. Disponível em: http:// web.bndes.gov.br/bib/jspui/handle/1408/16060. Acesso em: 15 mai. 2019.

MOORE, A. J. Quantifying the Landlocked Trade Penalty using Structural Gravity. Journal of Quantitative Economics, Mumbai, v. 16, n. 3, p. 769-786, 2018.

MORAES, A. L. M. O protecionismo agrícola internacional. Revista de Política Agrícola, Brasília, v. 5, n. 3, p. 20-32, 1996.

NHUONG, T.; WILSON, N.; HITE, D. Choosing the best model in the presence of zero trade: a fish product analysis. WorldFish Center Working Paper, Bayan Lepas, n. 2012-50, 2012.

ORGANISATION FOR ECONOMIC CO-OPERATION AND DEVELOPMENT/FOOD AND AGRICULTURE ORGANIZATION OF THE UNITED NATIONS. OECD-FAO Agricultural Outlook 2018-2027, OECD Publishing, Paris/Food and Agriculture Organization of the United Nations, Rome, Spain, 2018. Disponível em: https://doi.org/10.1787/agr_outlook-2018-en. Acesso em: 1 jul. 2019.

OHLAN, R. Growth and instability in dairy production and trade: a global analysis. International Journal of Trade and Global Markets, Geneva, v. 7, n. 2, p. 145$172,2014$. 
OHLIN, B. Interregional and international trade. Cambridge: Harvard University Press, 1933.

RENHE, I. R. T. O papel do leite na nutrição. Revista do Instituto de Laticínios Cândido Tostes, Juiz de Fora, v. 63, n. 363, p. 36-43, 2008.

RIBEIRO, S; FERRO, M. J. Why does language really matter? Evidence from EU and Mercosur Trade. In: Proceedings of the II International Congress on Interdisciplinarity in Social and Human Sciences. CIEO-Research Centre for Spatial and Organizational Dynamics, 2017. p. 68-78.

RICARDO, D. Sobre o comércio exterior. Princípios de Economia Política e Tributação, São Paulo: Abril Cultural, p. 101-112, 1982.

SANJUAN, A. I. et al. Analysing EU dairy exports: indicators of non-tariff measures and gravity. In: 2017 International Congress, August 28-September 1, 2017, Parma, Italy. European Association of Agricultural Economists, 2017.

SILVA, J. M. C. S.; TENREYRO, S. The log of gravity. The Review of Economics and statistics, Cambridge, v. 88, n. 4, p. 641-658, 2006.

SIQUEIRA, K. B.; LINHARES, L. F.; HOTT, M. C. Uma análise das barreiras tarifárias no comércio internacional de lácteos. Juiz de Fora: Embrapa Gado de Leite, 2011.

SMITH, A. A Riqueza das Nações: investigação sobre a natureza e suas causas. Volume I e II. Coleção Os Economistas. São Paulo: Nova Cultural, 1985.
TINBERGEN, J. Shaping the World Economy: suggestions for an international economic policy. New York: The Twentieth Century Fund, 1962.

VUONG, Q. H. Likelihood ratio tests for model selection and non-nested hypotheses. Econometrica: Journal of the Econometric Society, New Haven, v. 57, n. 2, p. 307-333, 1989.

WANG, C.; WEI, Y.; LIU, X. Determinants of bilateral trade flows in OECD countries: evidence from gravity panel data models. The World Economy, Nottingham, v. 33, n. 7, p. 894-915, 2010.

WOOLDRIDGE, J. M. Econometric analysis of cross section and panel data. 2. ed. Cambridge: MIT Press, 2010 .

WORLD BANK. "Population, total." World Development Indicators, The World Bank Group, 2019 revision, 2019. Disponível em: https://www.worldbank.org/. Acesso em: 09 de ago. 2019.

ZANINOTTO, P.; FALASCHETTI, E. Comparison of methods for modelling a count outcome with excess zeros: application to Activities of Daily Living (ADL-s). Journal of Epidemiology \& Community Health, London, v. 65, n. 3, p. 205-210, 2011.

ZHU, Y.; COX, T. L.; CHAVAS, J. An Economic Analysis of the Effects of the Uruguay Round Agreement and Full Trade Liberalization on the World Dairy Sector. Canadian Journal of Agricultural Economics/Revue canadienne d'agroeconomie, Victoria, v. 47, n. 5, p. 187-200, 1999. 


\section{ANEXO I - RELAÇÃO DOS PAÍSES CONSTANTES DA AMOSTRA:}

África do Sul, Albânia, Alemanha, Angola, Antígua e Barbuda, Argélia, Argentina, Armênia, Austrália, Bangladesh, Barbados, Belarus, Bélgica, Belize, Benin, Brunei, Bulgária, Burkina Faso, Cabo Verde, Camarões, Canadá, Catar, Chade, Chile, China, Chipre, Cingapura, Colômbia, Costa Rica, Cuba, Dinamarca, Djibuti, Dominica, El Salvador, Emirados Árabes Unidos, Equador, Espanha, Filipinas, França, Gabão, Gana, Geórgia, Granada, Guatemala, Guiana, Guiné, Guiné-Bissau, Haiti, Honduras, Índia, Indonésia,
Irlanda, Israel, Itália, Jamaica, Japão, Jordânia, Libéria, Madagascar, Malásia, Malaui, Mali, Malta, Marrocos, Maurício, Mauritânia, México, Moçambique, Namíbia, Nicarágua, Níger, Nigéria, Noruega, Nova Zelândia, Omã, Países Baixos (Holanda), Panamá, Paquistão, Paraguai, Peru, Polônia, Portugal, Quênia, Reino Unido, República Centro-Africana, República Dominicana, Rússia, Samoa, Seicheles, Senegal, Serra Leoa, Sri Lanka, Suécia, Suíça, Suriname, Tailândia, Tanzânia, Togo, Tonga, Trinidad e Tobago, Turquia, Ucrânia, Uruguai, Zâmbia. 